\title{
O estágio na formação de professores presencial e a distância: a experiência do curso de matemática da UFPEL'
}

The training in teacher education and distance learning: the experience of mathematics course from UFPEL

\author{
Nadiane Feldkercher \\ Maria das Graças Gonçalves Pinto \\ Universidade Federal de Pelotas
}

\section{Resumo}

Neste trabalho, objetivamos investigar como se desenvolvem os estágios nos Cursos de Licenciatura em Matemática a Distância e Presencial da Universidade Federal de Pelotas, na perspectiva de professores orientadores, coordenadoras de polo e alunos estagiários. Para a coleta de dados, utilizamos a entrevista individual e análise de documentos - Projetos Pedagógicos (PPs) dos dois Cursos. A análise esteve pautada na abordagem qualitativa e fundamentada, entre outros, em Pimenta e Lima (2004), Lima (2009) e nas orientações legais acerca do estágio. Percebemos que, nos dois cursos, a organização curricular do estágio é idêntica; que existem inúmeras limitações no desenvolvimento do estágio e que os estagiários concebem o estágio como o momento de colocar em prática as teorias, aproximando-se do futuro campo de atuação. Os estagiários do Curso a Distância sentem-se mais assessorados quanto à orientação e acompanhamento do estágio.

Palavras-chave: Estágio curricular supervisionado. Licenciatura em matemática a distância. Licenciatura em matemática presencial.

\section{Abstract}

In this study, we aim to investigate how training are developed in graduate distance and presence courses of mathematics in the Federal University of Pelotas, from the perspective of faculty advisers, coordinators and trainee students from centers. We used as data collection the individual interview and document analysis - Pedagogical Projects (PPs) of the two Courses. The analysis was based on a qualitative approach and based, among others, in Pimenta e Lima (2009), Lima (2009) and legal guidance about training. We realize that in the two courses the training curriculum organization is identical, the existence of numerous issues limit the development of training and the trainees perceive the training as a time to put into practice the theories studied, and to approaching themselves to their future field of action. The distance course trainees feel more guidance and monitoring advised of the training. Keywords: Supervised training. Degree in distance mathematics. Degree in presence mathematics. . 


\section{Apontamentos iniciais}

Um dos componentes que constitui qualquer curso de formação inicial de professores é o estágio curricular supervisionado, o qual é tomado como objeto deste trabalho. Para Leite; Ghedin e Almeida (2008, p. 33), no processo formativo do profissional professor, é necessário reconhecer o "[...] estágio como um elemento fundamental na formação profissional e como um dos espaços privilegiados para a formação do docente na concepção do professor crítico-reflexivo e na constituição dos saberes docentes necessários." Já para Lima (2009), o estágio na formação de professores é caracterizado pela aproximação do estagiário com a profissão docente, com profissionais da educação e com práticas docentes.

No Parecer do CNE/CP n 28 de 2001, o estágio curricular supervisionado é caracterizado como

[...] o tempo de aprendizagem que, através de um período de permanência, alguém se demora em algum lugar ou ofício para aprender a prática do mesmo e depois poder exercer uma profissão ou ofício. Assim o estágio curricular supervisionado supõe uma relação pedagógica entre alguém que já é um profissional reconhecido em um ambiente institucional de trabalho e um aluno estagiário. Por isso é que este momento se chama estágio curricular supervisionado. (BRASIL, 2001 , p. 8).

Assim, em cursos de formação de professores, espera-se que o estagiário permaneça por um determinado período na escola e/ou em sala de aula sendo supervisionado pelo professor da Escola Básica e orientado pelo professor da universidade, a fim de se aproximar do seu futuro campo de atuação, da profissão do professor e de suas práticas. É desejável que as aproximações entre esses sujeitos possuam um caráter de relação pedagógica, assumam-se como um trabalho orientado no sentido de proporcionar o aconselhamento, a partilha de saberes, a complementação de práticas pedagógicas, a busca de solução para os problemas e o diálogo entre os profissionais reconhecidos e o aluno estagiário (PIMENTA; LIMA, 2004). A orientação do estágio não se configura, portanto, em uma atividade controladora ou de disputa de poder e autoridade. É, ao contrário disso, um auxílio aos estagiários para que eles possam enfrentar as situações problemas encontradas no exercício da docência, como apontado por Azevedo e Abib (2008). 
Para Leite, Ghedin e Almeida (2008, p. 33), no processo formativo do profissional professor, é necessário reconhecer o "[...] estágio como um elemento fundamental na formação profissional e como um dos espaços privilegiados para a formação do docente na concepção do professor crítico-reflexivo e na constituição dos saberes docentes necessários". Com o desenvolvimento do estágio, com a execução das práticas de ensino, o aluno em formação tem a oportunidade de vivificar a aprendizagem do ser professor, de experienciar a futura profissão analisando e ajuizando o dia a dia desse exercício profissional. A vivência dos desafios e realizações diárias da profissão docente, no chão da escola, pode proporcionar ao professor em formação aprendizagens específicas de tal contexto, seja no tocante à escola, aos alunos dessa escola, bem como a outros fatores relacionados.

Aproxima-se dessa concepção o que pondera Lima (2009), que o estágio

[...] propõe-se a instrumentalizar o estagiário para a reflexão sobre o seu fazer pedagógico mais abrangente e a sua identidade profissional. Assim, estaremos conscientes de que o Estágio é um campo de conhecimento, uma aproximação do estagiário com a profissão docente e com os seus profissionais em seu local de trabalho, no concreto das suas práticas. (LIMA, 2009, p. 47).

Durante muito tempo - e não é de se estranhar que essa ideia ainda exista - o estágio curricular supervisionado em cursos de formação de professores era visto como o momento de se pôr em prática as teorias estudadas até então. Primeiramente, em sua formação, o aluno tinha uma preparação teórica que compreendia os fundamentos, estruturas, políticas, metodologias, história, filosofia, psicologia da educação, dentre outros. Posteriormente, ele poderia pôr em prática o que havia estudado, ou seja, poderia praticar a profissão de professor - no caso. Essa lógica é conhecida como o esquema 3+1: 3 anos de teorias e 1 ano de práticas de ensino.

Com a publicação das Diretrizes Curriculares Nacionais para a Formação de Professores da Educação Básica² e da Resolução CNE/CP $n^{\circ} 2 / 2002 a^{3}$ as discussões sobre o estágio na formação de professores se ampliaram, pois essas orientações exigiram que esse componente curricular tivesse 400 horas, iniciasse na segunda metade do curso e fosse desenvolvido em escola de Educação Básica. Da mesma forma, essas orientações indicam 
que a Prática como Componente Curricular também deve possuir no mínimo 400 horas e deve ser vivenciada ao longo do curso de formação de professores para a atuação em escola básica. Percebemos, então, que essas orientações desestabilizaram, muitas vezes positivamente, os modelos de cursos de formação de professores existentes, ainda inspirados no esquema $3+1$, e instigaram pesquisas referentes a essas "inéditas horas". (DIAS-DA-SILVA, 2005). Com base nas resoluções e do nosso tema de pesquisa, questionamo-nos: o que estamos fazendo com essas 400 horas de estágio? $\bigcirc$ que essas 400 horas trazem como resultado na formação desses "novos" professores?

A Resolução CNE/CP n 1/2002 propõe ainda que o estágio seja "[...] avaliado conjuntamente pela escola formadora e a escola campo de estágio." (BRASIL, 2002, Art. 13, § 3\%). Além disso, a Lei nº $11.788 / 2008$, que dispõe sobre o estágio obrigatório e não obrigatório de estudantes, destaca que o estágio deve "[...] ter acompanhamento efetivo pelo professor orientador da instituição de ensino e por supervisor da parte concedente" (BRASIL, 2008, Art. $3^{\circ}, \S 1^{\circ}$. Essas orientações reconhecem o papel formativo exercido pelo profissional formado que recebe o estagiário - no caso dos cursos de formação de professores, o professor da Escola Básica. Reconhecemos que o professor

142 da escola que recebe o estagiário exerce influência sobre a formação desse aluno e imprime-the modelos de ser professor a serem imitados e/ou negados. $\bigcirc$ professor da escola básica pode ser um grande parceiro do estagiário em seu processo de aprender a ser professor e marca significativamente suas primeiras experiências na profissão docente.

Como abordaremos a formação de professores de Matemática, consideramos pertinente verificar as Diretrizes Curriculares para os cursos de Matemática, mais especificamente o que se refere às orientações para o desenvolvimento do estágio curricular supervisionado nesse curso. Essas Diretrizes (Resolução do CNE/CES nº3/2003) concebem o estágio dos cursos de licenciatura em Matemática como essencial à formação do professor, como uma atividade que permite aos estagiários desenvolverem sequências de funções cada vez mais complexas, oportunizando-lhes assumir responsabilidades, desenvolver consciência sobre seu processo formativo e aprender, guiados por profissionais competentes e reconhecidos da sua área. Notamos nessas Diretrizes uma concepção de estágio curricular supervisionado muito interessante na medida em que o valoriza, enfatiza o exercício da docência e reconhece a supervisão como formativa. 
Via de regra, as orientações legais para os cursos de formação de professores, inclusive as que dizem respeito ao estágio curricular supervisionado, foram pensadas e elaboradas tendo como base os cursos presenciais. Diante dessa e de outras constatações, começamos a nos questionar quanto ao desenvolvimento do estágio curricular em um curso de formação de professores a distância.

Segundo o Decreto n 5.622/2005, que regulamenta a educação a distância no Brasil, o estágio obrigatório em qualquer curso a distância deve ser desenvolvido de forma presencial. Dessa forma, indagamo-nos: como seria o desenvolvimento do estágio para um aluno de curso a distância e para um aluno de curso presencial? $\bigcirc$ aluno a distância encontra maiores dificuldades que um aluno de curso presencial para a realização do estágio? Ou será que o aluno a distância possui um maior acompanhamento para desenvolver seu estágio, visto que conta com o apoio do professor orientador, do tutor a distância, do tutor presencial, da coordenadora de polo e possui o material didático ${ }^{4}$ de cada disciplina?

Percebemos que muitos são os estudos que abordam a formação de professores; parece estar em ascensão os estudos referentes aos estágios e à formação de professores a distância, entretanto não temos encontrado muitos estudos sobre estágio em cursos de formação de professores a distância ${ }^{5}$.

Nesse contexto, objetivamos, no presente trabalho, investigar como se desenvolvem os estágios nos cursos de licenciatura em Matemática a distância e presencial da Universidade Federal de Pelotas (UFPell, na perspectiva de professores orientadores, coordenadoras de polo e alunos estagiários.

A escolha pelos cursos de Licenciatura em Matemática ocorreu, já que, no momento do estudo, apenas estes contavam com turmas concluintes nas duas modalidades de ensino - presencial e a distância - e ambas as turmas estavam na última etapa do estágio curricular supervisionado - foco do nosso estudo.

Para a coleta de dados, utilizamos a entrevista individual e a análise de documentos - Projetos Pedagógicos (PPs) dos dois Cursos. As análises estiveram pautadas na abordagem qualitativa.

Tivemos como colaboradores da pesquisa ${ }^{6}$ quatro professores orientadores, três coordenadoras de polo e doze alunos estagiários vinculados ao Curso de Licenciatura em Matemática Presencial (CLMPY7 ou ao Curso de 
Licenciatura em Matemática a Distância $(C L M D)^{8}$ - o que totalizou 19 entrevistas. Os dados foram coletados no segundo semestre de 2009, através de colaboradores vinculados à disciplina de Estágio de Matemática II no CLMP e Prática de Ensino de Matemática II no CLMD.

Visto que os professores orientadores e as coordenadoras de polo já estavam definidos, selecionamos, apenas, os estagiários a serem entrevistados. Para tal, contamos com o auxílio dos professores orientadores que, a partir do critério de o aluno estar cursando a disciplina referente à regência de classe no Ensino Médio, indicaram nomes e e-mails desses estagiários. A partir dessas listas, fizemos contato e selecionamos, aleatoriamente, 6 alunos de cada curso. Não tivemos "controle" sobre os motivos que levaram os orientadores a indicar esses alunos. Os colaboradores do CLMD faziam parte da primeira edição do Curso ${ }^{9}$ que adotou características distintas das edições posteriores (como, por exemplo, aulas presenciais nos polos no início do Curso).

Em ambos os cursos sempre existem dois professores orientadores responsáveis pelas disciplinas de estágio, sendo um da área da Matemática e outro da Educação. $\bigcirc$ CLMD se diferencia por ter, em sua estrutura, a sede (Pelotas) e os polos educacionais (no caso estudado os polos se localizavam 144 nas cidades de Jaguarão, Turuçu e Canguçu - RS). Os profissionais que atuam na sede são: o coordenador do curso, os professores das disciplinas, os tutores da sede, funcionários e uma equipe de apoio técnico. Nos polos educacionais existem as coordenadoras de polo, os tutores do polo e um técnico em informática. Assim, enquanto que no CLMP são os professores orientadores que fazem as visitas supervisionadas aos estagiários, no CLMD são as coordenadoras e tutoras de polo que desenvolvem esse trabalho - sendo essa uma das justificativas da realização da entrevista com as coordenadoras de polo.

\section{O estágio no CLMD e CLMP na perspectiva dos colaboradores}

Tendo como base a nossa compreensão de estágio curricular supervisionado em cursos de formação de professores e a partir das falas dos colaboradores da pesquisa, organizamos quatro categorias de análises comuns a todos os colaboradores e uma categoria específica aos estagiários que são, respectivamente, organização do estágio, orientação do estágio, 
avaliação do estágio, limitações do estágio e sensações produzidas pelo estágio, as quais passamos a apresentar.

Conforme informações obtidas nos Projetos Pedagógicos dos cursos e pela fala de nossos colaboradores, podemos dizer que a organização do estágio nos dois cursos é bastante similar. Nesses cursos, a carga horária do estágio corresponde a 442 horas sendo que essas são distribuídas em 4 componentes curriculares com a mesma carga horária e objetivos. No CLMP o estágio é distribuído em Trabalho de Campo I (85 h/a); Estágio de Matemática I 136 h/a); Trabalho de Campo II (85 h/a) e Estágio de Matemática II (136 h/a) e as mesmas estão localizadas, respectivamente, no $5^{\circ}, 6^{\circ}, 7^{\circ}$ e $8^{\circ}$ semestres. Já no CLMD o estágio se organiza em Trabalho de Campo I (85 h/a), Prática de Ensino de Matemática I (136 h/a). Trabalho de Campo II (85 h/a) e Prática de Ensino de Matemática II $(136 \mathrm{~h} / \mathrm{a})$, desenvolvidos, respectivamente, no $5^{\circ}, 6^{\circ}, 7^{\circ}$ e $8^{\circ}$ semestre. Em ambos o estágio é desenvolvido em escola de Educação Básica, tanto no Ensino Fundamental (as duas primeiras disciplinas) quanto no Ensino Médio (as duas últimas disciplinas).

Nos dois cursos, o estágio inicia a partir da segunda metade do curso. Essa organização do estágio é evidenciada nas seguintes falas: O estágio no CLMD começa no $5^{\circ}$ semestre - que é a segunda metade do curso. Nesse semestre tem a disciplina de Trabalho de Campo I, que é a preparação para regência de classe no Ensino Fundamental: os alunos vão até a escola, conhecem a escola, conhecem a turma que pretendem realizar o estágio, o professor regente da disciplina de Matemática, analisam o Projeto Pedagógico da escola, veem no plano de estudo quais conteúdos terão que ministrar. A regência de classe no Ensino Fundamental ocorre no $6^{\circ}$ semestre e chama-se Prática de Ensino de Matemática I. Depois os alunos fazem o mesmo procedimento para o Ensino Médio: Trabalho de Campo Il e Prática de Ensino de Matemática II (Professora Kátia CLMD); No Trabalho de Campo II, os alunos coletam dados da escola, do ambiente escolar, da turma que vão trabalhar, eles têm contato com o professor, veem que conteúdos terão que ministrar e como o professor procede em sala de aula. Eles fazem as observações. No Estágio II, eles vão pra prática, vão pra sala de aula [...]. Isto também incluiu preparação de prova, correção, preparação de aula, participação em conselho, participação em reunião de área - em algumas escolas. (Professor Augusto, CLMP, 2010). 
Observamos que a organização dos estágios do CLMD e CLMP está de acordo com as orientações das Resoluções CNE/CP n 1 e 2/2002, ou seja, cumprem as 400 horas, iniciam a partir da segunda metade do curso e são desenvolvidos em escola de Educação Básica.

Segundo relato dos colaboradores vinculados ao CLMD, os estagiários não apresentaram dificuldades para desenvolver seus estágios ou para encontrar escolas que aceitassem alunos de cursos a distância, como expresso: Não tive problema [no estágio] por ser um curso a distância [...]. Tive todo o apoio da direção, dos funcionários, sempre no que precisei. Não tive nenhum problema, nem com os alunos. (Estagiária Helena, CLMD, 2009). Também não foram identificados aspectos particulares na realização do estágio em cada polo, ou seja, o desenvolvimento/organização do estágio nos três polos estudados foi similar.

A maioria dos colaboradores da pesquisa destacou como positiva a experiência de desenvolver o estágio tanto no Ensino Fundamental quanto no Ensino Médio, conforme demonstram os relatos: $O$ segundo estágio eles encararam bem melhor, já estavam mais maduros, já não ficavam tensos, nervosos como no primeiro. (Coordenadora de Polo Andressa, CLMD, 2010). É 146 importante fazer os dois estágios, no Ensino Fundamental e no Ensino Médio, para comparar, ver com que público tu vais te adaptar melhor enquanto professor. (Professora Kátia, CLMD, 2010). No primeiro estágio todos os colegas reclamavam [de suas turmas], mas eu tive uma excelente turma. Eu sabia que poderia encontrar uma turma ótima e uma nem tão boa. Então, a turma do segundo estágio não foi tão excelente. (Estagiária Elis, CLMD, 2010).

Segundo os colaboradores, realizar primeiro o estágio no Ensino Fundamental preparou melhor os estagiários para as atividades no nível médio, além de possibilitar conhecimento do público-alvo de cada nível de ensino. Essa avaliação positiva pode ser verificada na seguinte fala: No Estágio II, já me senti melhor como professor, talvez por interferência do Estágio I, por ele já ter me preparado. (Estagiário Lucas, CLMP, 2010).

Nos dois cursos, existe a orientação de os alunos desenvolverem a regência de classe durante o período de um bimestre ou um trimestre, dependendo do calendário da escola. Esse aspecto pode contribuir para que o estagiário tenha a possibilidade de iniciar e concluir determinadas tarefas e conteúdos com a turma com a qual desenvolve a regência de classe e, 
dessa forma, aproximar-se mais do trabalho realizado pelos professores e ter, segundo Leite, Ghedin e Almeida (2008), uma breve referência da complexidade que envolve o trabalho docente.

Uma crítica perceptível dos colaboradores dos dois cursos foi o fato de que, muitas vezes, o projeto de ensino que se desenvolve no Trabalho de Campo não pode ser seguido, tendo em vista vários fatores, com destaque para a necessidade de troca de escolas - como expressa essa fala: alguns alunos observaram numa escola e não puderam estagiar nessa escola. (Professora Fernanda, CLMP, 2010). Muitos estagiários desenvolveram a regência de classe em uma escola diferente da qual realizaram as observações, em uma distinta turma para a qual tinham desenvolvido o projeto de ensino. Esse fato ocorreu devido a limitações das escolas, incompatibilidade de horários, dentre outros. Destacamos que esse seria um ponto a ser revisto para um possivel desenvolvimento do estágio de forma mais proveitosa, pois, conforme apontam as críticas, a maneira como esses fatos vêm sendo conduzidos não colabora para que os alunos atinjam os principais objetivos do estágio.

Uma diferença percebida nos PPs quanto à organização dos estágios nos dois cursos diz respeito ao nome do componente curricular que objetiva a regência da classe: enquanto que no curso presencial é chamado de Estágio (I e II), no curso a distância é chamado de Prática de Ensino (I e II), porém as duas disciplinas possuem o mesmo propósito, a mesma organização, inclusive com a mesma carga horária.

Outra diferença do CLMD em relação ao CLMP é que os estagiários desse curso desenvolvem o estágio inclusive na zona rural e na periferia, o que não é comum nos cursos presenciais. A coordenadora de polo Andressa mencionou que "algumas escolas eram na colônia" e destacou que realizaram o sorteio de escolas/turmas entre os estagiários devido à grande demanda por estágio em matemática em uma cidade de pequeno porte como Turuçu. Devido à grande demanda por estágio em escola básica na disciplina de matemática os estagiários desse polo do CLMD desenvolveram os estágios para além das escolas situadas no centro da cidade. Contraditoriamente, Santos; Brand e Zamperetti (2009), por meio de suas experiências como professoras orientadoras de estágio, principalmente de cursos presenciais, constatam que, normalmente, os estágios não são desenvolvidos na zona rural ou em periferias. 
De forma geral, percebemos que, nos dois cursos, predomina um modelo de estágio centrado na observação, planejamento e regência de classe, como já nos alertava Pimenta e Lima (2004). Esse modelo de estágio segue a mesma organização de quando a carga horária de estágio era substancialmente menor do que a atual. Notamos também que, nos dois cursos, o estágio é focado prioritariamente na docência em sala de aula, não abordando aspectos da gestão escolar ou atuação em ambientes não escolares. Essa priorização da docência em sala de aula durante o estágio também foi constatada nos estudos de Azevedo e Abib (2008).

Quanto à orientação do estágio, destacamos que, mesmo que a maioria dos estagiários não perceba, essa inicia com o Trabalho de Campo I. Nesse âmbito, são feitas leituras e encaminhamentos para que os estagiários comecem as atividades de estágio nas escolas, o que se refere ao segundo componente curricular de estágio nos dois cursos.

No CLMP e no CLMD, os três grupos de colaboradores enfatizaram que a orientação do estágio ocorre principalmente pela procura dos estagiários, sendo que os possíveis orientadores (professores, tutores da sede e do polo, coordenadora de polo) ficam à disposição, como mencionado: A orien148 tação ocorria mais pela procura dos alunos, marcávamos por e-mail com o professor um encontro (Estagiária Carolina, CLMP, 2010); sempre tinha alguém que tu poderias contar, mesmo a distância. (Estagiária Laura, CLMD, 2009).

Nas falas dos colaboradores dos dois cursos, o acompanhamento do estágio pareceu estar mais vinculado ao orientador do curso de Matemática. Em alguns casos, o orientador vinculado à área da Educação esteve ausente das falas dos colaboradores e por outras foi criticado, conforme enunciaram os alunos: no Estágio II tem um professor da matemática e um da pedagogia e só o professor da matemática se interessou em nos acompanhar. A outra professora se ausentou, eu não sei o que aconteceu, não nos informaram. (Estagiária Vitória, CLMP, 2010/. Quem eu mais busquei para dúvidas foi a professora da matemática, ela era a segunda mais importante da disciplina, antes tinha o professor da Faculdade de Educação [... El Ela me dava dicas quando solicitava. (Estagiário João, CLMD, 2009).

Diante desses destaques dos estagiários, percebemos que a proposta de trabalho compartilhado e cooperativo no acompanhamento dos estágios curriculares supervisionados, tentando relacionar conhecimentos específicos da 
matemática e pedagógicos, como destacado nos Projetos Pedagógicos dos Cursos, pode não estar sendo totalmente efetivada.

A orientação que o estagiário recebe após a visita supervisionada foi apontada como significativa pelo fato de ser um retorno aos estagiários, como também poder possibilitar melhorias no trabalho pedagógico desenvolvido pelos alunos, como revela essa fala: Depois que as tutoras e coordenadora de polo fazem a visita elas vêm e dizem o que a gente fez, onde pecamos, o que está bem. (Estagiário Pedro, CLMD, 2010). Esses achados são corroborados com o que pensam Rela; Rocha e Carvalho (2007), de que os orientadores devem emitir feedback sobre o trabalho desenvolvido pelo estagiário, a fim de corrigir e melhorar as suas práticas pedagógicas.

Foi indicado ainda que o professor titular de Escola Básica pouco acompanha o trabalho desenvolvido pelo estagiário, como evidenciado nessas falas: No geral os professores titulares orientavam muito pouco os estagiários [...] Raros foram os casos em que o professor titular assistia à aula dos estagiários. A maioria deixava o estagiário à vontade e aguardava na secretaria ou fazia seus planejamentos. (Coordenadora de Polo Denise, CLMD, 2010). Talvez as professoras titulares tivessem confiança no meu trabalho e me deixavam sozinho. Eu era o professor, elas não iam, não iam nem ver, nem perguntar o que acontecia, nem estavam na escola. (Estagiário Leandro, CLMP, 2010).

Não podemos elencar os motivos que levam alguns professores titulares a se afastarem e ficarem ausentes da sala de aula quando recebem um estagiário. Diante desse fato evidenciado pelos nossos entrevistados, questionamo-nos: que papel formativo esses professores da escola básica assumiram junto ao estagiário?

$\bigcirc$ que foi denunciado pelos nossos colaboradores diverge do Parecer CNE/CP no 28/2001 que orienta que o professor da Escola Básica seja um supervisor do estagiário. É preciso, então, que o professor titular conscientize-se que pode tanto orientar quanto aprender com o estagiário. Ademais, a universidade também precisa pensar e desenvolver estratégias para reconhecer o papel do professor titular para com a formação dos professores. E será que o acompanhamento e a orientação, por parte do professor titular ao estagiário, imprimem ganhos à formação inicial desse professor? Acreditamos que sim. E, de outra forma, quais são os motivos que levam o professor titular a se afastar da sala de aula quando recebem um estagiário? 
Uma das divergências quanto à orientação do estágio nos dois cursos é o fato de ser desenvolvida presencialmente entre orientador e estagiário no CLMP e via tecnologias entre orientador e estagiário no CLMD. Dessa forma, os alunos do CLMD preferem buscar orientações junto aos tutores e coordenadora de polo visto que esses se encontram diariamente no polo educacional, como expressa este depoimento: As tutoras e a coordenadora do polo estavam sempre no polo. A qualquer hora você poderia tirar as dúvidas. (Estagiária Elis, CLMD, 2010). Os tutores e coordenadora de polo tiram dúvidas dos estagiários, orientam-nos na elaboração dos planos de aula e conversam após a visita supervisionada. Assim, os estagiários do CLMD possuem um acompanhamento mais próximo ou tem maiores oportunidades de orientações em relação aos alunos do CLMP, visto que esses últimos só têm orientação se agendarem um dia e horário com o orientador, como revelado neste fragmento: Você podia marcar orientação por e-mail. (Estagiário Leandro, CLMP, 2010).

$\bigcirc$ tutor da sede não foi destacado como um possível orientador das atividades de estágio pelos colaboradores do CLMD. Conhecendo as funções desempenhadas pelo tutor da sede como, por exemplo, a função de revisar os planos de aula postados pelos alunos, entendemos que ele também é um

150 orientador das atividades desenvolvidas pelo estagiário, porém, nos discursos, esse profissional ficou ausente.

Outra questão a se realçar é que os professores orientadores do CLMD trabalharam os quatro componentes referentes ao estágio com essa primeira turma. Os tutores de polo e a coordenadora de polo - os quais realizaram as visitas supervisionadas - também foram os mesmos no CLMD durante as 4 disciplinas do ECS. Já os professores orientadores de estágio do CLMP não foram os mesmos em todas as disciplinas, além de que, durante uma mesma disciplina ocorreram trocas de professores. Esses fatos fizeram com que os estagiários do CLMD evidenciassem um maior acompanhamento de suas atividades bem como confiassem no trabalho desenvolvido por esses profissionais responsáveis pela orientação de estágio. De outra forma, os estagiários do CLMP sentiram-se perdidos e desassistidos nesse aspecto.

Ainda quanto à orientação de estágio no CLMP e CLMD, é possível realçar que, de uma forma ou outra, tanto professores orientadores de estágio quanto professores titulares da Escola Básica, coordenadora de polo, tutores de polo e da sede desenvolvem a função de orientar ou supervisionar o estágio, mesmo que os estagiários não os reconheçam como tal. No Curso a Distância 
existe um maior número de profissionais responsáveis pelo assessoramento do estágio curricular supervisionado, o que dinamiza o seu desenvolvimento. Esse fato dos diferentes sujeitos supervisionando e orientando o estágio no CLMD aproxima-se do que é argumentado por Azevedo e Abib (2006, p. 7): "[...] a forma em se realizar esta orientação e este tutoramento, podem melhor preparar os futuros professores para a docência."

que percebemos pela fala de nossos colaboradores é que os estagiários do Curso a Distância sentem-se mais amparados devido ao contato que possuem com esses distintos orientadores. Destacamos que a existência desses distintos profissionais no CLMD se dá também pelos recursos financeiros que esse projeto de educação a distância recebe e pela contrapartida da Prefeitura Municipal de Educação que recebe o polo educacional em sua cidade.

Os instrumentos utilizados para a avaliação do estágio nos dois cursos foram os mesmos: projeto de ensino, visitas supervisionadas e relatório de estágio - considerados os mais recorrentes na área. Nem o CLMP nem o CLMD inovaram quanto ao método de avaliação dos estágios.

Nos dois cursos, a entrega do relatório referente à regência de classe significou o fim do estágio. Diante dessa limitação, concordamos com Rela; Rocha e Carvalho ao ponderarem que

Os cursos de formação de professores não podem mais propor espaços isolados para a experiência prática, que faz com que, por exemplo, o estágio se configure como algo com finalidade em si mesmo e se realize de modo desarticulado com o restante do curso. Neste sentido, cabe aos professores planejar a organização curricular de forma a possibilitar a articulação entre o saber e o saber fazer. Neste sentido, propor oficinas, seminários, grupos de trabalho supervisionado, com vistas a promover e ao mesmo tempo exigir dos futuros professores atuações diferenciadas, diferentes modos de organização do trabalho, possibilitará a vivência e o desvelamento de diferentes competências. (RELA; ROCHA; CARVALHO, 2007, p. 35).

desenvolvimento de atividades de reflexão e sistematização após a regência de classe proporcionaria aos estagiários outra formação, outro modo de perceber a prática docente e a profissão do professor, visto que essas atividades seriam orientadas por professores reconhecidos e experientes. É possível não continuarmos fazendo da entrega do relatório final o fim do estágio e 
propormos atividades, inclusive de retorno à escola campo, que promovam o desenvolvimento desses professores em formação.

$\bigcirc$ professor titular da Escola Básica não avaliou o estagiário em nenhum dos cursos, o que contraria a orientação da Resolução CNE/CP n 1 de 2002 ao destacar que o estágio deve "[...] ser avaliado conjuntamente pela escola formadora e a escola campo de estágio." (BRASIL, 2002).

Além disso, nenhum dos cursos deu retorno do estágio às escolas campo tomando-as como um espaço para o desenvolvimento de uma atividade obrigatória para a formação de professores. Diante desse fato, ajuizamos como Fazenda (1991, p. 61) que embora "[...] existam vários bloqueios ao nosso trabalho, desde o de ordem política, até as questões burocrático-administrativas, penso que é dever da Universidade discutir com a rede de ensino algumas experiências desenvolvidas em seu âmbito." Apontamos esse como um fato a ser repensado no âmbito do desenvolvimento dos estágios nos cursos de formação de professores.

Um aspecto diferencial no CLMD, que não ocorre no CLMP, foi que todos os planos de aula dos estagiários eram revisados antes da aplicação, como destacado nesta fala: O plano de ensino e os planos de aula postados no moodle eram avaliados. A gente avaliava e disponibilizava a nota para que eles tivessem o retorno de como estavam indo. (Professor Anderson, CLMD, 2010). Essa revisão dos planos pode adquirir um caráter significativo para a formação desses professores e pode contribuir para o aperfeiçoamento das práticas docentes dos estagiários. Conhecendo a dinâmica de funcionamento do CLMD, reconhecemos os tutores da sede como os responsáveis por este trabalho, apesar de eles não terem sido mencionados pela maioria dos colaboradores.

Uma das divergências quanto à avaliação dos estágios nos dois cursos é que no CLMD esse processo envolve mais sujeitos - como já sinalizado também no item referente à orientação do estágio. Enquanto que no CLMP, normalmente, só um orientador avalia, no CLMD a avaliação é feita pelo professor orientador, pelos tutores de sede, pelos tutores de polo e pela coordenadora de polo. A avaliação do estágio no CLMD é feita de forma compartilhada envolvendo mais de um profissional.

A visita supervisionada do estágio no CLMD é feita por, no mínimo, dois profissionais - a coordenadora de polo com formação em Pedagogia e o tutor de polo com a formação em Matemática - que tem como tarefa avaliar 
os estagiários tanto em relação a aspectos pedagógicos quanto ao domínio do conteúdo de Matemática - o que parece estar sendo cumprido. O seguinte relato descreve esse processo: O ideal era fazer duas visitas para cada estagiário. Lá eu e uma tutora da matemática. Eu observava a parte pedagógica e ela conteúdos de matemática. (Coordenadora de Polo Leonice, CLMD, 2009).

Já no CLMP normalmente os professores orientadores têm dificuldades para realizar as visitas supervisionadas aos estagiários. Diante das dificuldades (de horário, de deslocamento...) os dois professores orientadores acabam dividindo as tarefas, repartindo os alunos e, assim, cada orientador visita um determinado número de estagiários - conforme registro: Nós dividimos a turma e o professor de matemática fazia a observação de alguns e eu de outros alunos [...]. Também dividimos os relatórios dos estagiários para ler e depois nos reunimos para elaborar o resultado final. (Professora Fernanda, CLMP, 2010).

Consideramos a prática de visitas supervisionadas do CLMD muito interessante essencialmente se a comparamos com os múltiplos casos existentes em cursos presenciais em que somente um professor universitário é "colocado" como o único responsável pela orientação e acompanhamento de uma turma inteira de estagiários. É nítida a diferença de condições que esses profissionais possuem. E terá esse tipo de avaliação compartilhada (Pedagogia/Educação + Matemática) algum destaque em relação à avaliação feita por somente um profissional formado em Matemática?

De acordo com o que relataram os estagiários, percebemos que as visitas supervisionadas do CLMP variam em quantidades de zero a dois, enquanto que no CLMD a frequência foi de um a três. Os alunos do CLMP e os próprios professores reconhecem que a quantidade de visitas é limitada ou insuficiente, como destacado nestes fragmentos de fala: Tentamos fazer três visitas, mas não foi possivel devido a problemas de atraso no início do semestre, em função da gripe 10, a questão dos horários, deu um problema na própria CRE aqui de Pelotas [...]. (Professor Augusto, CLMP, 2010). No Estágio II o professor da Matemática foi uma vez na escola, eu acho isso pouco. Ele deveria ter ir pelo menos no início e no final pra ver a evolução do aluno. (Estagiária Ana, CLMP, 2010).

No CLMD as visitas supervisionadas possuem um peso, uma nota enquanto que no CLMP, segundo os orientadores, a visita serve como apoio para a avaliação do aluno, não possuindo especificamente um peso. 
Provavelmente, o CLMD atribui um peso a regência de classe por serem outros profissionais que avaliam os trabalhos escritos. Por outro lado, é possível nos questionarmos sobre a não atribuição de um peso à regência de classe no CLMP: estaria a "teoria" tentando sobrepor-se à "prática"? Ou os orientadores não estão tendo condições de realizar da maneira como gostariam as visitas?

As limitações do estágio foram similares no CLMP e no CLMD. Dentre as principais limitações, destacam-se as normas da Coordenadoria Regional de Educação, as regras estabelecidas pelas próprias escolas, a divergência entre os calendários das escolas e da universidade, a gripe $\mathrm{A}$, a dificuldade dos alunos em elaborar planos de ensino, a dificuldade de locomoção para as escolas por parte dos estagiários e dos professores responsáveis pelas visitas, o pouco contato do professor orientador vinculado a área da Educação com os estagiários, o comportamento dos alunos da Escola Básica, as especificidades do ensino noturno e o cursar outras disciplinas juntamente com o desenvolvimento da regência de classe - referente ao estágio. As seguintes falas relatam um pouco dessas dificuldades: Tivemos a paralisação em função da gripe. Também houve essa questão da alta procura de estagiários na CRE de Pelotas. (Professor Augusto, CLMP, 2010). Os estagiários tinham dificul-

154 dade para elaborar os planos de aula (Coordenadora de Polo Leonice, CLMD, 2009). Fiquei chateado por ter que mudar de escola do Trabalho de Campo I para o Estágio I. (Estagiário Vitor, CLMD, 2009). Senti a falta de interesse pelo estudo de muitos alunos adolescentes. (Estagiária Paola, CLMP, 2010).

De certa forma, compreendemos as normas e regras estabelecidas pela Coordenadoria Regional de Educação e pelas próprias escolas referentes ao desenvolvimento do estágio. Como destacado por Santos; Brand e Zamperetti (2009), com a ampliação das horas de estágio, as escolas se viram "invadidas" e "vigiadas" pelos estagiários que dela necessitam para realizar observações e regência de classe. Assim, para manter certa ordem, a CRE e as escolas fazem algumas exigências.

As limitações específicas ao CLMP foram as frequentes trocas de professores orientadores de estágio, a dificuldade de o professor orientador fazer a visita supervisionada e a falta de um acompanhamento/orientação mais próximo do estagiário. Uma estagiária fez a seguinte observação: Teve muita mudança de professores no Trabalho de Campo I, mudança do professor da área da educação do Trabalho de Campo I para o Estágio I. (Estagiária Carolina, CLMP, 2010). Principalmente pela fala dos estagiários do CLMP, 
percebemos que o conjunto das limitações enfrentadas no desenvolvimento do estágio pode estar restringindo suas possibilidades de desenvolver um trabalho de estágio com mais qualidade.

As limitações particulares ao CLMD, que foram destacadas especialmente pelas coordenadoras de polo, dizem respeito à falta de escolas no município para o desenvolvimento dos estágios (evidenciado pelas Coordenadoras Andressa e Leonice) e a falta de formação das tutoras de polo e da coordenadora de polo para atuarem no estágio (Coordenadora Leonice).

As limitações encontradas tanto no desenvolvimento do estágio do Curso Presencial quanto do Curso a Distância demonstram que elas podem ser comuns à realização do estágio em qualquer contexto. Percebemos nessas limitações enfrentadas no desenvolvimento do estágio curricular em cursos de formação de professores uma lacuna para estarmos pensando em soluções para as mesmas, sendo que as experiências em distintos contextos podem ser tomadas como exemplo para outros, a fim de aprimorarmos essa prática e traçarmos alternativas para essas questões.

As sensações produzidas pelo estágio nos estagiários são muito similares nos dois cursos. Teve proeminência entre os estagiários que o estágio é o momento de colocar em prática tudo o que se aprendeu até então, como expresso nos seguintes depoimentos: O estágio é hora de a gente conciliar teoria que a gente vê em sala de aula com a prática. É hora de a gente colocar teoria na prática. (Estagiária Helena, CLMD, 2009). Com o estágio [é possivel ter] uma noção do que é ser professor de verdade porque antes a gente ficava só na teoria. Não tivemos prática antes do estágio. (Estagiária Paola, CLMP, 2010).

Parece que ainda se tem a ideia de que no estágio o aluno é retirado da hibernação teórica e convidado a conhecer o cotidiano de sala de aula e exercer sua prática pedagógica. Essa "hibernação" já era denunciada antes da Resolução do CNE/CP n²/2002a - que orienta sobre as práticas a serem desenvolvidas ao longo do curso - por vários pesquisadores da área, a exemplo de Fazenda (1991).

A maioria dos estagiários não consegue perceber a dimensão prática de seus cursos. Para eles, a prática é a regência de classe. Possivelmente, existe uma carência no entendimento do que é teoria e do que é prática para esses colaboradores. De outra forma, indicamos a necessidade da recuperação da 
concepção de indissociabilidade entre teoria e prática na formação de professores (PIMENTA; LIMA, 2004) e da ideia de que o estágio não é o momento de aplicação de teorias.

Ademais, levantamos outro questionamento: o que os cursos estão fazendo com as 400 horas referentes à Prática como Componente Curricular que deveria ser desenvolvida ao longo do curso? Por que os estagiários somente reconhecem na regência de classe a sua formação prática? Dias-daSilva (2005) nos dá alguns indícios de respostas a essas questões ao enunciar que com a imposição das 800 horas de Estágio e de Prática,

A questão central passou a ser aritmética: impregnados por uma cultura organizacional legalista, acostumada ao estabelecimento de currículos mínimos para cursos de graduação, aliada aos eternos embates bacharelado\&licenciatura, o resultado imediato dessas resoluções para nossas universidades se reduziu ao loteamento de horas na grade curricular, com conseqüências desastrosas para a construção do conhecimento dos futuros professores. (DIAS-DASILVA, 2005, p. 388).

Muitos estagiários mencionaram que o estágio possibilitou-thes reafirmar a escolha profissional, aproximarem-se da escola, da sala de aula e da profissão docente - o que, segundo Lima (2009), é o desejado para o estágio. Essas aproximações proporcionadas pelo estágio podem ser identificadas no seguinte depoimento: Foi uma experiência impar que me proporcionou o contato com a realidade, uma sala de aula, com da profissão do professor de Matemática. (Estagiária Helena, CLMD, 2009).

Quando os estagiários iniciaram a regência de classe, relataram que sentiram insegurança e nervosismo, o que foi desaparecendo no decorrer das aulas, como mencionado: Eu já tinha feito magistério então já tinha uma base. No primeiro estágio foi engraçado, era EJA. Eu entrei na turma e era bem nova e muitos alunos eram mais velhos do que eu. Então tive um pouco de insegurança. Três, quatro dias eu fiquei meio insegura, pensando: será que eles estão gostando? E no dia da visita da professora, como vai ser? Mas depois conheci mais os alunos e melhorou. (Estagiária Laura, CMD, 2009).

Com o andamento das atividades de estágio, muitos estagiários se decepcionaram, ou ficaram surpresos com o que ocorre ou deixa de ocorrer no dia-a-dia da Escola Básica. O comportamento difícil dos alunos e a 
"matação" de aula no ensino noturno foram os aspectos que mais desmotivaram os estagiários. $\bigcirc$ seguinte relato demonstra um pouco da desmotivação causada nos estagiários: No Estágio II, no lo ano do Ensino Médio noturno [...] preparei muitas atividades e não conseguia aplicar. Poucos alunos aprenderam. Num dia eu ia dar aula tinha uns alunos, outro dia tinha outros alunos que eu nunca tinha visto. Aquela também foi a época da gripe, quando chovia os alunos não vinham. [...] A maioria dos alunos da noite trabalha e quando iam pra aula estavam cansados e usavam isso como desculpa para ir embora. Muitos tinham família, filhos. Outros só estudavam de noite pra poder namorar. (Estagiária Carolina, CLMP, 2010). A gente vai pro estágio com todo gás, com uma vontade de fazer tanta coisa e chega na escola e é tudo diferente. Você conversa com os professores e todos dizem estar cansado, reclamam muito. Então você se decepciona. Os alunos não vêm pra escola e os professores acham normal [...] Se eu for trabalhar com licenciatura vou trabalhar com turmas diurnas porque ensino noturno eu me decepcionei bastante. (Estagiária Laura, CLMD, 2009).

Diante dos relatos, nos perguntamos: para que escolas estamos formando nossos futuros professores? $\bigcirc$ que podemos concluir é que o estágio é um território de conflitos. Os estagiários evidenciam isso ao relatar o choque que têm com a realidade da escola. Esse choque também está demonstrando o distanciamento entre universidade e Escola Básica durante o processo formativo desses profissionais, fato já denunciado por Fernandes e Silveira (2007). Portanto, apontamos aqui mais um fator a ser repensado no âmbito da formação de professores: como aproximar universidade e escola? Quais as alternativas possíveis?

Apesar de visualizarmos muitas limitações e depararmo-nos com muitos questionamentos, como Azevedo e Abib (2006, p. 2), ainda vemos nos estágios "[...] uma excelente oportunidade para o fortalecimento da formação dos futuros professores, o estabelecimento de parcerias entre universidade-escola e a integração da formação inicial e continuada dos professores desde que sejam valorizados alguns aspectos fundamentais." 


\section{Considerações possíveis}

De forma geral, percebemos muitas convergências no desenvolvimento do estágio curricular supervisionado do CLMP e do CLMD. Ressalvamos que os dados foram coletados com colaboradores vinculados às turmas de formandos de 2009/2 do CLMD e do CLMP. Os colaboradores do CLMD pertenciam à primeira edição do curso, referente ao projeto Pró-Licenciatura (Pró-Lic) - Fase I. Com isso destacamos que Edições posteriores do CLMD podem render outras informações e análises.

Por mais que um curso seja ofertado na modalidade presencial e outro na modalidade a distância, ambos adotam a mesma organização ou desenho curricular para o estágio. A essência do estágio nos dois cursos é composta pela observação, planejamento e regência de classe - modelo tradicional de estágio. Será que a adoção do mesmo modelo de desenvolvimento de estágio para os dois cursos é o ideal? Não deveriam existir modelos de estágio próprios aos cursos presenciais e a distância? Se a dinâmica de funcionamento de um curso a distância é diferente daquela de um curso presencial lo CLMD é desenvolvido basicamente via moodle, web conferência, vídeoaulas e material impresso e o CLMP tem como base as aulas presenciais e materiais didáticos) porque os estágios dessas duas modalidades de formação de professores são similares?

Indicamos que a organização do estágio nos dois cursos pode se repensada, inovada a fim de propor melhorias para a formação desses futuros professores de matemática, buscando superar a mera transposição de atividades para preencher o número de horas previsto para esse componente curricular.

As divergências do desenvolvimento do estágio nos dois cursos ocorrem principalmente pelo fato de o CLMD contar com profissionais (coordenadora de polo, tutores de polo e de sede) e com um investimento financeiro que não existem no curso presencial. Dessa forma, percebemos que, quanto à orientação do estágio, os alunos do CLMD sentem-se mais assessorados do que os do CLMP por terem o contato diário com os tutores de polo e com a coordenadora de polo, o que não acontece na relação dos estagiários do CLMP com seus professores orientadores. Devido, também, ao maior número de profissionais envolvidos no estágio do CLMD, mais profissionais avaliam esse componente curricular e, consequentemente, seus estagiários. Esse fato pode 
estar se evidenciando em um trabalho de caráter compartilhado e cooperativo. Outro adicional a essa sensação de maior acompanhamento e assessoramento dos estágios no CLMD se deu pelo fato de os profissionais que nele atuam serem os mesmos nos quatro semestres letivos. Já o CLMP enfrentou a falta de professores e sua troca frequente. Sem dúvida, esses fatores estão deixando marcas na formação desses professores na modalidade presencial e a distância.

A partir das percepções dos colaboradores dessa pesquisa, apontamos a necessidade de se repensar o modelo de orientação ou acompanhamento de estágio. Talvez seja necessário um maior número de profissionais trabalhando com a orientação de estágio principalmente no CLMP. Talvez seja necessário nos dois cursos um projeto de trabalho que aproxime mais universidade e escola e considere o professor titular da Escola Básica como um orientador essencial para a formação inicial desses professores.

As limitações e sensações produzidas pelo estágio, de forma geral, são as mesmas. Tanto no curso presencial quanto no curso a distância, a limitação que teve maior ênfase foi a burocracia ou as normas impostas pela Coordenadoria Regional de Educação e pelas escolas para a concessão dos estágios. Quanto às sensações produzidas pelo estágio aos estagiários, segundo eles este é o momento de se colocar em prática as teorias estudadas até então. Esse entendimento enfatiza, mais uma vez, o quão complexa é a tarefa de articular teoria e prática nos cursos de formação de professores e o quão difícil é a compreensão do que se caracteriza como formação teórica e o que se caracteriza como formação prática. Ainda, referente às sensações, consideramos positivo o fato de os estagiários reconhecerem que o estágio os aproxima das escolas, da profissão do professor, dos alunos e das práticas de ensino.

As limitações no desenvolvimento do estágio, sejam elas de qualquer ordem, são difíceis de evitar. Portanto, evidenciamos a importância e a necessidade da intensificação do trabalho de orientação do estágio, caracterizado pelo aconselhamento, partilha de saberes, busca de solução para os problemas e diálogo (PIMENTA; LIMA, 2004) entre estagiário e orientador - seja ele professor da universidade ou da escola. Inclusive a noção de que o estágio não é 'aplicação de teorias' e a ajuda no processo de construção identitária dos professores em formação podem ser melhoradas em face dessa intensificação da orientação do estágio. 
Especificamente ao desenvolvimento do estágio no CLMD, ficam algumas indagações: para além do Decreto n 5.622/2005, por que o estágio no CLMD ocorre de forma presencial? Qual é a concepção de estágio que perpassa o projeto de formação de professores do CLMD? Será o estágio no CLMD "o momento" para se mostrar que o curso é de formação de professores e, portanto, os estagiários precisam ir para as escolas? $\bigcirc$ estágio estaria sendo assumido como "o momento decisivo" para a formação desses professores? Essas questões podem ser estendidas ao CLMP e, no seu conjunto, evidenciam possibilidades de outros estudos e pesquisas sobre a temática.

Poderia esperar-se que o CLMD, por ser um curso novo, na modalidade a distância, apresentasse um modelo de estágio diferente daquele configurado pela observação, planejamento e regência de classe, o que não ocorreu (nem no CLMD, tampouco no CLMP). Parece que o CLMD (e também o CLMP) não pensou em alternativas ou em uma maneira própria para o desenvolvimento do estágio. Um novo modelo de estágio adotado pelo CLMD poderia ser um provocador de mudanças para o estágio em cursos de formação de professores presenciais no momento em que propusesse novas metodologias ou novas formas de desenvolvimento.

Nesse contexto de novas propostas para o desenvolvimento do estágio, concordamos com Fernandes e Silveria (2007, p. 3) quando argumentam que "[...] pensar em estágio é falar em projeto de curso, em formação específica e formação pedagógica, é tocar no calcanhar de Aquiles dos processos educativos: teoria e prática; conteúdo e forma; modos de produção do conhecimento." Com esse princípio, demonstramos também que concebemos o estágio como uma atividade complexa, que deve levar em consideração muitos aspectos e que não é de fácil execução.

A realização dessa pesquisa fez-nos perceber a necessidade do desenvolvimento de pesquisas abordando esse tema, inclusive com proposições que contribuam para superar uma visão em parte ainda conservadora sobre o papel dos estágios obrigatórios em cursos de formação de professores para a ałuação em escola básica. Entendemos o estágio curricular como uma oportunidade do aluno exercer sua futura profissão, pensar criticamente sobre sua formação, deparar-se com limites no desenvolvimento de suas práticas pedagógicas, dentre outros. Não assumimos o estágio como a atividade máxima da formação de professores, mas como um momento singular, com o 
potencial de desenvolver melhorias nas aprendizagens do ser professor; portanto, merece ser pensado e refletido constantemente.

\section{Notas}

1 Este artigo apresenta, sinteticamente, a pesquisa de Mestrado em Educação realizada pelo Programa de Pós-Graduação em Educação da Universidade Federal de Pelotas. A dissertação na íntegra encontra-se disponível em: <http://www.ufpel.edu.br/tede/tde_busca/arquivo. php? codArquivo $=949>$.

2 Resolução do CNE/CP n 1/2002.

3 Institui a duração e a carga horária dos cursos de formação de professores.

4 Material preparado para ser utilizado durante o desenvolvimento de cada disciplina; apostila.

5 A afirmativa está pautada, dentre outros, em um levantamento sobre os estudos referentes ao estágio na formação de professores presencial e a distância. Esse levantamento perpassou, em especial, os artigos publicados na Revista Brasileira de Educação (2003 a 2009), na Revista Educação \& Sociedade (2003 a 2009) e os painéis do Encontro Nacional de Didática e Prática de Ensino (2006 e 2008).

6 Para preservar as identidades, usamos nomes fictícios definidos aleatoriamente e respeitando o gênero dos sujeitos. Todos os colaboradores aceitaram participar da pesquisa e concordaram com o Termo de Consentimento Livre e Esclarecido.

7 Turma do diurno.

8 Tivemos autorização para divulgar o nome dos cursos.

9 Pertencente ao projeto Pró-Licenciatura (Pró-Lic) - Fase I, mais especificamente com três polos educacionais localizados no Rio Grande do Sul, nas cidades de Jaguarão, Turuçu e Canguçu.

10 Doença respiratória aguda que afetou muitas pessoas no inverno de 2009 no Brasil, especialmente no Sul. Assim, muitos estabelecimentos, como escolas e universidades, tiveram que suspender suas atividades por um determinado período, o que influenciou no desenvolvimento dos estágios no contexto pesquisado.

\section{Referências}

AZEVEDO, Maria Antonia Ramos de; ABIB, Maria Lúcia Vital dos Santos. Os estágios supervisionados e os estilos de orientação. In: ENCONTRO NACIONAL DE DIDÁTICA E PRÁTICA DE ENSINO, 13; 2006, Recife. Anais... Recife: UFPE, 2006.

AZEVEDO, Maria Antonia Ramos de; ABIB, Maria Lúcia Vital dos Santos. O papel do professor formador frente os cenários educacionais no seu trabalho de orientação de estágios. In: 
ENCONTRO NACIONAL DE DIDÁTICA E PRÁTICA DE ENSINO, 14; 2008, Porto Alegre. Anais... Porto Alegre: PUC, 2008.

BRASIL. Ministério da Educação. Conselho Nacional de Educação. Conselho Pleno. Parecer n 28/200 1: Dá nova redação ao Parecer CNE/CP no 28/2001, que estabelece a duração e a carga horária dos cursos de Formação de Professores da Educação Básica, em nível superior, curso de licenciatura, de graduação plena. Brasília, Conselho Nacional de Educação, 2001.

Conselho Nacional de Educação. Conselho Pleno. Resolução n 1, de 18 de fevereiro de 2002: Institui Diretrizes Curriculares Nacionais para a Formação de Professores da Educação Básica, em nível superior, curso de licenciatura, de graduação plena. Brasília, Conselho Nacional de Educação, 2002.

Conselho Nacional de Educação. Conselho Pleno. Resolução n² 2, de 19 de fevereiro de 2002a: Institui a duração e a carga horária dos cursos de licenciatura, de graduação plena, de formação de professores da Educação Básica em nível superior. Brasília, Conselho Nacional de Educação, 2002.

Conselho Nacional de Educação. Câmara de Educação Superior. Resolução nº 3, de 18 de fevereiro de 2003: Estabelece as Diretrizes Curriculares para os cursos de 162 Matemática. Brasília, Conselho Nacional de Educação, 2003.

Ministério da Educação. Secretaria de Educação Profissional e Tecnológica. Decreto n 5.622, de 19 de dezembro de 2005: Regulamenta o art. 80 da Lei no 9.394, de 20 de dezembro de 1996, que estabelece as diretrizes e bases da educação nacional. Brasília, Secretaria de Educação Profissional e Tecnológica, 2005.

Lei $n^{0} 11.788$, de 25 de setembro de 2008: Dispõe sobre o estágio de estudantes. Brasília, Subchefia para Assuntos Jurídicos, 2008.

COORDENADORA de pólo Andressa, CLMD. Entrevista oral. Turuçu, 20 jan. 2010.

COORDENADORA de pólo Denise, CLMD. Entrevista oral. Canguçu, 12 jan. 2010.

COORDENADORA de pólo Leonice, CLMD. Entrevista oral. Jaguarão, 11 dez. 2009.

DIAS-DA-SILVA, Maria Helena Galvão Fren. Política de formação de professores no Brasil: as ciladas da reestruturação das licenciaturas. Perspectiva, Florianópolis, v. 23, n. 02, p. $381-406$, jul./dez. 2005.

ESTAGIÁRIA Ana, CLMP. Entrevista oral. Pelotas, 20 jan. 2010.

ESTAGIÁRIA Carolina, CLMP. Entrevista oral. Pelotas, 05 jan. 2010. 
ESTAGIÁRIA Elis, CLMD. Entrevista oral. Pelotas, 06 jan. 2010.

ESTAGIÁRIA Helena, CLMD. Entrevista oral. Jaguarão, 11 dez. 2009.

ESTAGIÁRIA Laura, CLMD. Entrevista oral. Pelotas, 16 dez. 2009.

ESTAGIÁRIA Paola, CLMP. Entrevista oral. Pelotas, 29 jan. 2010.

ESTAGIÁRIA Vitória, CLMP. Entrevista oral. Pelotas, 26 jan. 2010.

ESTAGIÁRIO João CLMD. Entrevista oral. Pelołas, 14 dez. 2009.

ESTAGIÁRIO Leandro CLMP. Entrevista oral. Pelotas, 29 jan. 2010.

ESTAGIÁRIO Lucas CLMP. Entrevista oral. Pelotas, 04 fev. 2010.

ESTAGIÁRIO Pedro CLMD. Entrevista oral. Turuçu, 20 jan. 2010.

ESTAGIÁRIO Vitor CLMD. Entrevista oral. Jaguarão, 11 dez. 2009.

FAZENDA Ivani Catarina Arantes. O papel do estágio nos cursos de formação de professores. In: PICONEZ, Stela Conceição Bertholo (Org.). A prática de ensino e o estágio supervisionado. Campinas: Papirus, 1991.

FERNANDES, Cleoni Maria Barboza; SILVEIRA, Denise Nascimento da. Formação inicial de professores: desafios do estágio curricular supervisionado e territorialidades na licenciatura. In: REUNIÃO ANUAL DA ASSOCIAÇÃO NACIONAL DE PÓS-GRADUACCÃO E PESQUISA EM EDUCAÇÃO, 30; 2007, Caxambu. Anais... Caxambu: ANPEd, 2007.

LEITE, Yoshie Ussami Ferrari; GHEDIN, Evandro; ALMEIDA, Maria Isabel. Formação de professores: caminhos e descaminhos da prática. Brasília: Líber Livro Editora, 2008.

LIMA, Maria Socorro Lucena. O estágio nos cursos de licenciatura e a metáfora da árvore. Pesquiseduca, Santos, v. 1, n. 1, p. 45-48, jan./jun. 2009.

PIMENTA, Selma Garrido; LIMA, Maria Socorro Lucena. Estágio e docência. 2. ed. São Paulo: Cortez, 2004.

PROFESSOR Anderson, CLMD. Entrevista oral. Pelotas, 01 fev. 2010.

PROFESSOR Augusto, CLMP. Entrevista oral. Pelotas, 22 jan. 2010.

PROFESSORA Fernanda CLMP. Entrevista oral. Pelotas, 30 jan. 2010.

PROFESSORA Kátia CLMD. Entrevista oral. Pelotas, 14 jan. 2010. 
RELA, Eliana; ROCHA, Karla; CARVALHO, Marie Jane. Estágio na formação de professore no contexto das novas tecnologias de informação - princípios norteadores e desafios a serem enfrentados. Informática na Educação: Teoria \& Prática, Porto Alegre, v. 10, n. 1, p. 29-40, jan./jun. 2007.

SANTOS, Rita de Cássia Grecco dos; BRAND, Rita Melânia Webler; ZAMPERETTI, Maristani Polidori. "Dívidas" entre Universidade e escola? Pensando o estágio como espaço-tempo de formação inicial e continuada de professores. In: CONGRESSO INTERNACIONAL DE EDUCAÇÃO, 6, 2009, São Leopoldo. Anais... São Leopoldo: UNISINOS, 2009.

UNIVERSIDADE FEDERAL DE PELOTAS. Instituto de Física e de Matemática. Curso de Licenciatura em Matemática. Projeto Pedagógico Licenciatura em Matemática. Pelotas, UFPel: 2009.

Instituto de Física e de Matemática. Licenciatura em Matemática a Distância. Projeto

Pedagógico: Pró-Licenciatura Fase I. Pelotas, UFPel: 2008.

Profa. Ms. Nadiane Feldkercher Universidade Federal de Pelotas | UFPel

Faculdade de Educação

Doutoranda do Programa de Pós-Graduação em Educação |UFPel

Bolsista CAPES/DS Grupo de Estudos e Pesquisas | Estágio e Formação de Professores | GEPEFOP E-mail | nadianefel@yahoo.com.br

Profa. Dra. Maria das Graças Gonçalves Pinto Universidade Federal de Pelotas Faculdade de Educação Programa de Pós-Graduação em Educação Líder do Grupo de Estudos e Pesquisas | Estágio e Formação de Professores | GEPEFOP E-mail | profgra@gmail.com

Recebido 15 ago. 2012 Aceito 10 jan. 2012 